\title{
Editor-in-Chief, European Spine Journal: call for nominations and applications
}

The European Spine Journal (ESJ) is a leading peerreviewed journal founded 22 years ago and dedicated to the spine sciences. It is the official publication of several spine societies, most important among them Eurospine-the Spine Society of Europe (SSE) and the German Spine Society. The ESJ brings readers the latest clinical and basic research and informed opinions that shape today's spinal practice-invasive and noninvasive - and promote the practice of evidence-based medicine. With contributions from leading international clinicians and researchers, the ESJ aims to be among the premier journals providing a global perspective to advance knowledge of the spinal disorders. The ESJ publishes content valuable to both spinal generalists and highly focused specialists on all aspects of spinal research, diagnosis, and treatment by offering Original Papers, Review Articles, Technical Innovations, Grand Rounds, and Case Reports, as well as focus issues in the form of supplements. In the past few years the ESJ has successfully started to build an online video library of surgical interventions executed by leaders in the field.

The ESJ seeks an individual to serve as the journal's next Editor-in-Chief who will uphold and enhance the journal's educational mission, editorial quality, and reputation for meaningful scholarship. The applicant must be a respected and accomplished spine specialist who is well organized, energetic, innovative, and dedicated to continuing the tradition of the journal as an important, timely, and respected resource for the medical community. The successful applicant will have experience as an editor, associate editor, or productive editorial board member for a peer-reviewed journal. Responsibility for the content of the ESJ rests entirely with the Editorin-Chief and the Editorial Board, but the Editor-in-Chief must also be willing to work collaboratively with the journal's publisher, Springer, and the affiliated societies to ensure that the journal meets the expectations of spinal professionals and the "market". The journal's editorial office is located near Bern, Switzerland, where an efficient and experienced staff awaits the new Editor-in-Chief. The applicant must be comfortable working with electronic technology in order to expedite review and publication of submitted manuscripts. The new Editor-in-Chief will officially assume responsibility for the ESJ by 1 January 2014 but must be prepared to help facilitate the editorial transition beginning in the fall of 2013.

Interested individuals should submit an application that includes the following no later than 19 July 2013:

- A curriculum vitae

- A succinct letter of interest, stating the candidate's qualifications and outlining how she/he envisages accommodating the time demands of editing the journal

- A vision statement of 700 words or less for the next 3 years of publication of ESJ. Items of specific interest to the Search Committee include:

- The primary aims for the direction of the journal, to include

- Organization and responsibilities of the editorial office and any Deputy, Associate and Advisory Editors

- Types of content and editorial features

- Involvement with and enhancements to online features and presentation

Applications and questions for the Search Committee should be submitted by e-mail to Gabriele Schroeder of Springer (gabriele.schroeder@springer.com) and must be received by Friday 19 July 2013. If you would like to nominate someone for consideration, please provide that person's name and contact information, with a brief statement of your reasons for the nomination, no later than 1 July 2013. 